\title{
Obstructive sleep apnea and obesity: implications for public health
}

\begin{abstract}
Obstructive sleep apnea (OSA) is a global disease with a rising incidence along with its comorbidities, especially with metabolic syndrome. One of the main components contributing to sleep apnea is obesity; as well as diabetes mellitus type 2 (T2DM), hypercholesterolemia, and hypertension. OSA is a condition that requires management and the disease can be treated by using CPAP therapy. The awareness of this global issue is rising, and health care systems are providing preventive measures, diagnosis and the treatment options. The major preventable risk factors to decrease obesity are the awareness of lifestyle modification (eating behaviors, smoking, drinking alcohol, etc.) and understanding the importance of exercise. If these lifestyle modifications are widely applied, then not only will the consequences of obesity and sleep apnea be reduced, but also the incidence of cardiovascular disease will decrease greatly. Public awareness of the importance of weight loss by lifestyle modification or bariatric surgery to improve the quality of life is needed. These preventive actions, screening measures, and treatment strategies for obesity and OSA can significantly reduce the incidence of obesity, as well as OSA and the related comorbidities such as cardiovascular disease, atherosclerosis, and depression. Finally, health care costs will also be reduced.
\end{abstract}

Keywords: exercise, obesity, OSA, public health, sleep
Volume I Issue 4 - 2017

\author{
Shazia Jehan,' Ferdinand Zizi,' Seithikurippu \\ R Pandi-Perumal,'2 Steven Wall,' Evan \\ Auguste, ${ }^{3}$ Alyson K Myers, ${ }^{4}$ Giradin Jean- \\ Louis,' Samy I McFarlane ${ }^{5}$ \\ 'Department of Population Health, Center for Healthful \\ Behavior Change, USA \\ ${ }^{2}$ Somnogen Canada Inc, Canada \\ ${ }^{3}$ Fordham University, USA \\ ${ }^{4}$ Department of Medicine, North Shore University Hospital, \\ USA \\ ${ }^{5}$ Department of Medicine, SUNY Downstate Medical Center, \\ USA
}

Correspondence: Samy I McFarlane, Distinguished Teaching Professor of Medicine and Endocrinology, State University of New York-Downstate Medical Center, Brooklyn District President, American College of Physicians, 450 Clarkson Avenue, Box 50, Brooklyn, I I 203, New York, USA, Tel 7I 8-270-37 I , Fax 718-270-6358, Email smcfarlane@downstate.edu

Received: August 04, 2017 | Published: December 12, 2017
Abbrevations: OSA, obstructive sleep apnea; T2DM, type 2 diabetes mellitus; MetS, metabolic syndrome; CVD, cardiovascular diseases; AHI, apnea-hypopnea index; SDB, sleep disordered breathing; BMI, body mass index; OSAS, obstructive sleep apnea syndrome; CRP, c-reactive protein; TNF- $\alpha$, tumor necrosis factor $\alpha$; HRT, hormone replacement therapy; PSG, polysomnographic; CPAP, continuous positive airway pressure

\section{Introduction}

Obesity incidence is increasing globally; the prevalence of obesity in Asian countries has risen to about $30 .^{1}$ There is a linear correlation between obesity and OSA. In obese people, fat deposits in the upper respiratory tract narrow the airway; there is a decrease in muscle activity in this region, leading to hypoxic and apneic episodes, ultimately resulting in sleep apnea. These hypoxia/apnea episodes lead to a decrease in oxygen that is available in body tissues and blood vessels. The decreased oxygenation causes tissue hypoxia, which is the main contributing factor to atherosclerosis, the main risk factor for Cardiovascular Diseases (CVD). ${ }^{2}$

A four-year longitudinal study ${ }^{3}$ of overweight and obese American adults demonstrates that change in weight is directly proportionate to sleep disordered breathing (SDB). Those with the greatest weight gain had a more severe apnea-hypopnea index (AHI). The risk of OSA increases with age and body mass index (BMI); other associated factors seen in a cohort of Australian men includes sedentary lifestyle, tobacco abuse, and heavy alcohol use. ${ }^{4}$ OSA is strongly correlated with multiple disease conditions, including type 2 diabetes mellitus
(T2DM), hyperlipidemia, hypertension, heart failure, cardiovascular diseases (CVD) and depression., ${ }^{4,5}$

\section{Obesity and sleep}

Obesity is defined as a $\mathrm{BMI} \geq 30$, whereas a $\mathrm{BMI} \geq 25.0$ indicates the person is overweight. ${ }^{6}$ Compared to men, women have lower rates of being overweight or obese. The major contributing factors to obesity include environment, eating behavior, and physical inactivity. Psychosocial circumstances and genetics also play important roles in obesity. $^{7}$

People who are obese (with a BMI of more than 30) with shorter sleep duration have twice as many subjective sleep problems compared to non-obese people. ${ }^{8}$ Being obese or overweight is associated with decreased amount of sleep compared to non-obese patients. ${ }^{9}$ Obesity is associated with poor sleep quantity and quality; thus weight reduction can ameliorate sleep problems. ${ }^{10,11}$ As a result preventing weight gain had a positive effect on sleep quality and duration in adult Black women ${ }^{12}$ (Figure 1).

Weight gain is a slow process sustained by lifestyle factors such as lack of sleep, sedentary lifestyle, excessive caloric intake, and genetics. Short sleepers and obese people can easily suffer major depression. In male Chinese subjects, obesity has also been associated with short sleep duration (less than 6 hours) and prolonged working hours (greater than 9 hours) ${ }^{13}$ Short sleep duration and dietary intake can cause hormonal imbalances. One such imbalance is a decrease in melatonin, leading to alterations in the metabolic circadian rhythm predisposing to weight gain and metabolic syndrome. ${ }^{14}$ There are 
also alterations in the actions of the hormones leptin and insulin. Obese individuals develop resistance to both of these hormones. These hormones decrease food need and increase energy metabolism. Ghrelin, which is released by the stomach stimulates appetite and is also affected by sleep disturbances. An increase in the level of ghrelin and a decrease in the level of leptin is also noted in chronic short sleepers. ${ }^{15,16}$ These altered levels in short sleepers predispose to obesity because of the associated increased food intake..$^{14,17-19}$ Factors which predispose to obesity, such as poor sleep and excessive caloric intake are also the major predisposing factors for diabetes and the other components of the metabolic syndrome. ${ }^{20-24}$ OSA has furtherreaching consequences than simply being tired, in OSA patients, excessive daytime sleepiness, anxiety, and poor concentration due to lack of sleep can lead to traffic accidents ${ }^{25}$ (Figure 2).

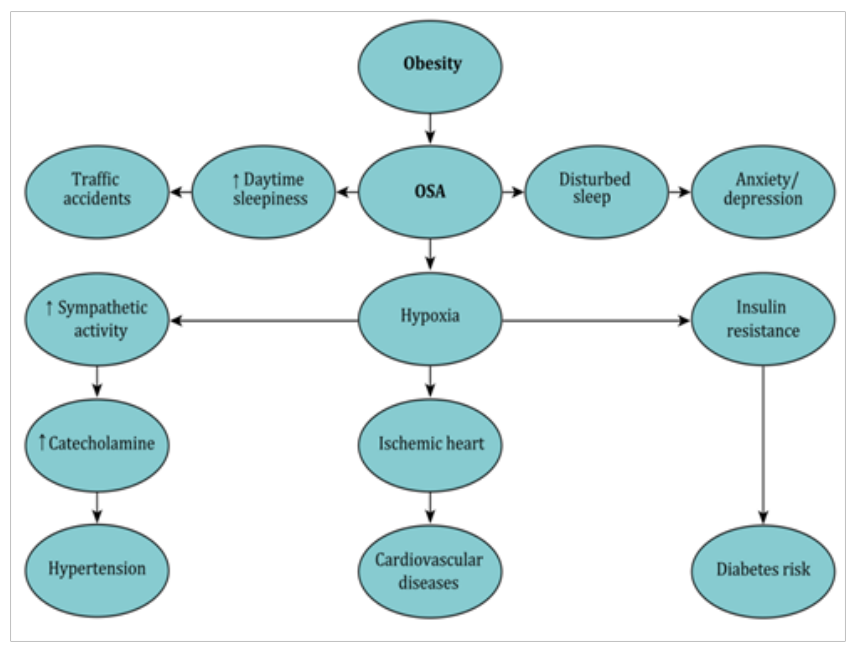

Figure I A schematic diagram that shows the obesity and associated comorbidities.

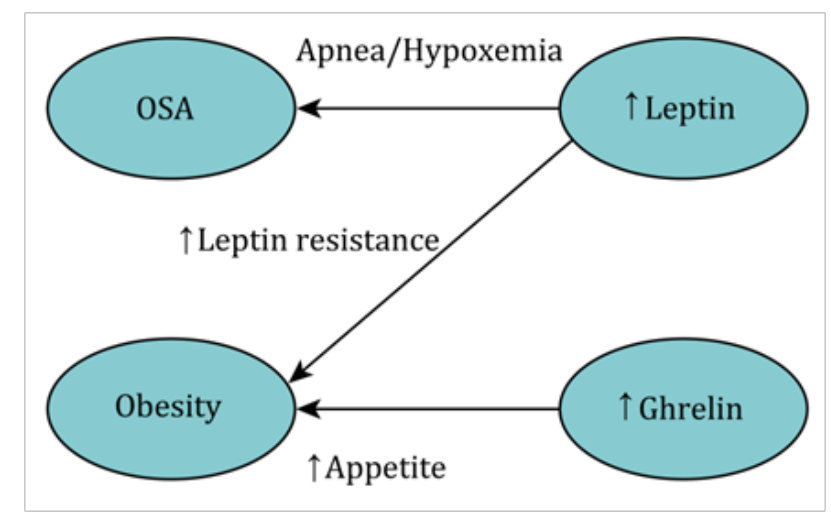

Figure $2 \mathrm{~A}$ schematic diagram that shows the correlations between OSA, Obesity, Leptin, and Ghrelin.

\section{Obstructive sleep apnea syndrome}

In obstructive sleep apnea syndrome (OSAS), patients experience recurrent apnea and hypopnea episodes due to the complete or partial collapse of the upper airway. In obese people, the narrowing of upper respiratory muscles occurs because of the accumulation of fatty tissues. The obstruction in breathing due to the narrowing of the upper airway causes a marked increase in intrathoracic pressure and triggers apnea and hypoxia. ${ }^{26}$ There is an increased sympathetic activation due to apnea/hypoxia episodes in OSAS patients. ${ }^{27}$ Episodes of hypoxemia/ apnea can drop the oxyhemoglobin saturation from $95 \%$ to $80 \%$, depending on the length of the period of apnea. OSA is an independent risk factor for cardiovascular and cerebrovascular diseases. Due to the hypoxia-related to OSAS, the oxidative stress leads to overproduction of reactive oxygen species, which can cause endothelial dysfunction and result in atherosclerosis. The inflammatory marker C-reactive protein (CRP), tumor necrosis factor $\alpha$ (TNF $\alpha$ ), and interleukin-6 (IL-6) were increased in patients with OSA and significantly elevated when the AHI was 15 or greater. ${ }^{28}$

Leptin is a hormone involved in feeding and metabolizing energy. Increased levels of leptin are found in patients with OSAS. The level of leptin hormone is correlated with the severity of OSAS. ${ }^{29}$ Another study shows that increased levels of the leptin hormone are present in both obese and obstructive sleep apnea patients, with the leptin level being directly proportional to the severity of the syndrome..$^{30}$ In OSA patients, serum leptin levels are $50 \%$ higher compared to controls.

\section{Epidemiology, prevalence and gender differences in OSA}

The prevalence of OSA in the general population is 3 to $7 \%$ for men and 2 to $5 \%$ for women. ${ }^{31}$ The rates are especially high for those who are obese. The converse is also true: those with OSA are at risk for obesity. Inadequate sleep during the night and daytime sleepiness predispose patients to weight gain. ${ }^{32}$ The prevalence of sleep apnea in obese people who go for bariatric surgery is $77 \%$. Polysomnographic (PSG) testing is recommended for all obese people who are candidates for bariatric surgery. ${ }^{33}$

The rates of OSA vary amongst women based on their menopausal status. In premenopausal women, the prevalence of OSA is $0.6 \%$, which is very low. Postmenopausal women who are on hormone replacement therapy (HRT) have a prevalence of $0.5 \%$; however, postmenopausal women who do not use HRT have a higher prevalence: $2.7 \%$. Post-menopausal women not on HRT have rates of OSA almost equal to that of men. ${ }^{34}$ The prevalence of OSA is higher in men than women, with the exception of postmenopausal women. ${ }^{35}$ Despite the increased prevalence of sleep apnea in men, women present with increased comorbidities, including a morning headache, insomnia, mood problems, and anxiety. ${ }^{36}$

\section{Differences in ethnicity}

Most studies done in regards to ethnicity differences and OSA have been done between Blacks and Whites. In a cross-sectional study of OSA prevalence in South Asian patients with T2DM compared to that of white Europeans, whites were nearly twice as likely to have OSA (36.2\% vs. $51.4 \%)$. In addition, the severity of the condition was lower for South Asians than for Europeans ${ }^{37}$ In the Sleep Heart Health Study, a multi-ethnic cohort was studied to explore the symptoms of $\mathrm{SDB}$ in relation to race and ethnicity. Frequent snoring was more common in Hispanic men and woman as well as Black women compared to others. ${ }^{38}$ In African-Americans, the risk of OSA is seen at a younger age than in whites. ${ }^{39}$ In a study comparing Far East Asian men with white men, OSA was more common and more severe in Far East Asian men, although they had a lower BMI. ${ }^{40}$ Authors noted that craniofacial differences may play a role in these increased rates of OSA in Far East Asian men. In the Middle East, obesity plays a bigger 
role in OSA. A review article exploring this topic found that studies were done in countries such as Dubai, United Arab Emirates found up to $22 \%$ of participants are at risk for OSA (Table 1$){ }^{41,42}$

Table I A highlights on the worldwide studies concerning OSA, obesity, and related comorbidities

\begin{tabular}{|c|c|c|c|c|c|c|c|}
\hline Study title & Study design & $\begin{array}{l}\text { Total number } \\
\text { (N) }\end{array}$ & $\begin{array}{l}\text { Major associated } \\
\text { comorbidities }\end{array}$ & Obesity & $\begin{array}{l}\text { Sleep } \\
\text { disturbances } \\
\text { (OSA) }\end{array}$ & P-values & Reference \\
\hline $\begin{array}{l}\text { Quality of sleep and risk for } \\
\text { obstructive sleep apnea in } \\
\text { ambulant individuals with } \\
\text { T2DM at a tertiary referral } \\
\text { hospital in Kenya: A cross- } \\
\text { sectional, comparative study. }\end{array}$ & $\begin{array}{l}\text { Cross-sectional, } \\
\text { comparative study }\end{array}$ & $\begin{array}{l}223 \text { males }+ \\
\text { females }\end{array}$ & $\begin{array}{l}\mathrm{T} 2 \mathrm{dm}, \\
\text { hypertension, } \\
\text { depression, COPDS }\end{array}$ & Positive & Positive & 0.001 & 5 \\
\hline $\begin{array}{l}\text { Sleep apnea in Australian men: } \\
\text { Disease burden, co-morbidities, } \\
\text { and correlates from the } \\
\text { Australian longitudinal study } \\
\text { on male health. }\end{array}$ & Longitudinal study & $\begin{array}{l}13,423 \text { adult } \\
\text { males }\end{array}$ & $\begin{array}{l}\mathrm{T} 2 \mathrm{dm}, \\
\text { hypertension, } \\
\text { depression }\end{array}$ & Positive & Positive & $<0.001$ & 4 \\
\hline $\begin{array}{l}\text { Longitudinal study } \\
\text { of moderate weight } \\
\text { change and SDB. }\end{array}$ & $\begin{array}{l}\text { Prospective } \\
\text { cohort study }\end{array}$ & $\begin{array}{l}690 \text { males }+ \\
\text { females }\end{array}$ & Anxiety/depression & Positive & Positive & 0.01 & 3 \\
\hline $\begin{array}{l}\text { Short sleep duration combined } \\
\text { with OSA is associated with } \\
\text { visceral obesity in Korean }\end{array}$ & $\begin{array}{l}\text { Cross-sectional } \\
\text { study. }\end{array}$ & $\begin{array}{l}838 \text { males }+ \\
\text { females }\end{array}$ & Anxiety/depression & Positive & Positive & $<0.001$ & 42 \\
\hline
\end{tabular}

adults

Association

of short sleep duration with

weight gain and obesity at

1-year follow-up: A large-scale

Prospective

35,247 males

Anxiety/depression Positive Positive

$<0.01$

\section{Treatment implications}

Weight loss, physical activity, and diet control: Obesity and low levels of physical activity are associated with moderate to severe OSA. Exercise helps in decreasing weight, blood pressure, depression, anxiety, and fatigue. ${ }^{28}$ Eating disorders such as bulimia can also be the causative factor of obesity; these mental and psychological issues should be addressed to overcome obesity and its comorbidities in early childhood or at the earliest age of diagnosis. ${ }^{43}$ To prevent adult obesity, early childhood prevention by families is key in controlling this global issue. Unfortunately, high-quality studies in this area are greatly lacking. ${ }^{44}$

CPAP: The conventional treatment for OSA is continuous positive airway pressure (CPAP). This therapy uses a machine to deliver a constant airflow to a patient's airway via a nasal, facial, or oral device that maintains airway patency during sleep. CPAP treatment significantly relieves OSAS symptoms and improves functional status in both males and females. Women's physiological changes during pregnancy and menopause lead to different sleep patterns and clinical presentations of OSAS when compared to men. ${ }^{28}$

Avoidance of lying in a supine position or, using topical nasal corticosteroids are other therapeutic approaches. The psychoactive drug modafinil has also prescribed to patients who do not respond to CPAP effectively. ${ }^{45}$

Weight loss by surgical procedures: In the primary care setting, physicians performing BMI screenings markedly increased from 2008 to 2013 from $54 \%$ to $73 \%$. However, the management and 
implications of obesity at primary healthcare facilities still need to be improved, and behavioral-based treatment should be given priority. ${ }^{46}$

Weight loss is the key factor in the treatment of OSA. It can be achieved with exercise, diet changes, and/or medications. One study showed that short sleepers (less than 7 hours) had improvement in metabolic indices and greater weight loss when they increased their sleep more than 7 hours. ${ }^{47}$ Short sleepers (6 hours or less) who go to sleep late tend to eat later at night, increasing their daily intake of calories and becoming more prone to gain weight. ${ }^{48}$

Surgical procedures are more beneficial than medical procedures for losing weight and addressing the comorbidities associated with obesity. If dieting and increased sleep measures fail, then bariatric surgery could be an alternative treatment option to lose weight. After losing weight through bariatric surgery, OSA, and metabolic derangements greatly improved. ${ }^{49,50}$ While the treatment combination CPAP and surgery to lose weight has beneficial effects in the treatment of OSA, patients need close monitoring to prevent surgical complications. ${ }^{51}$

There was a great improvement noticed in OSA on polysomnographic studies before and after the surgical procedure; improvements were also noticed in metabolic syndrome. Bariatric surgery is becoming the major treatment option for patients in which weight loss through diet, exercise, and CPAP therapy has failed. ${ }^{52-54}$ In obese renal transplant patients, LSG (laparoscopic sleeve gastrectomy) surgical procedures greatly reduce the post-transplant complications. ${ }^{55}$ Another study shows bariatric surgery reduces microvascular complications, especially in those with prediabetic state. $^{56}$

The concentration of the enzyme heme oxygenase is increased in patients with severe OSA and morbid obesity; bariatric surgery decreases this enzyme concentration. As result, inflammatory process and insulin resistance decrease. Obesity-related OSA is best treated by a combination of surgical procedures and CPAP therapy. ${ }^{51,57}$ OSAS and obesity are correlated problems; while treating OSAS, obesity should also be addressed in obese patients, even if that means using surgical procedures. ${ }^{58}$

Complications of surgical procedures: There are very few microvascular complications noted with bariatric surgery. In patients with pre-diabetes, it is actually more beneficial in preventing microvascular complications such as diabetic nephropathy, neuropathy, and retinopathy. ${ }^{56}$ Obese patients who have previously undergone bariatric surgery who subsequently cardiac surgery, have a higher risk of coronary artery complications compared to patients with no previous bariatric surgery. ${ }^{59}$

People who have bariatric surgery are also at increased risk for vitamin deficiencies, depending on the type of procedure. Vitamin B deficiencies are often reported after bariatric surgical procedures, and the patients can develop neurological complications, such as muscle weakness, polyneuropathy, and abnormal gait. Wernicke-Korsakoff neuropathy is one side effect that is not reversible; other complications can be treated by taking vitamins ${ }^{60}$ After bariatric surgery, bleeding, ulceration, fistula formation, and stenosis of the anastomosis can occur; all these complications can be repaired endoscopically or in an open procedure. ${ }^{61}$

\section{Public health implications}

To prevent obesity and its serious complications, patients as well as policymakers, health care workers, marketing and food industries all play a role. ${ }^{62}$ To prevent obesity and its complications, early childhood development interventions mediated by parents and family education is also very important. Preparing healthy meals, increasing physical activities, and encouraging lifestyle modifications at an early age. Early childhood education about what constitutes a healthy lifestyle and its adoption are very important. Parents can make children more active by involving them in chores or encouraging play beyond video games. Also adopting healthier cooking methods such as baking or grilling instead of frying food should be emphasized. Avoidance of foods with high fructose corn syrup such as juice or soda is also important. Ironically in Australia, obesity persists despite a national dietary campaign which has led to a reduction in sugary beverage consumption. ${ }^{63}$ Local community campaigns can gain attention and motivate people to avoid sugary drinks and other sugar-filled beverages and food. This avoidance and awareness might be detrimental to soda industries and other sugar manufacturing products globally, but this will allow us to appropriately address this rising global problem and its comorbidities worldwide. ${ }^{64}$ Engaging the entire family in making healthy choices leads to a healthy society in the future. ${ }^{65}$

To improve public health, healthcare workers must address the important lifestyle modifications of diet and exercise, as well as the proper duration and quality of sleep. ${ }^{66}$ Public messages should be given that emphasize the harmful effects of excessive food intake and lack of physical exertion. ${ }^{67}$ Primary care physicians can play a vital role in preventing obesity and related comorbidities by educating patients, recommending different strategies, and involving a multidisciplinary team of healthcare workers to provide effective obesity therapy and prevention to their patients. A dietician can be an integral part of this team as dieticians can aid patients in developing adoption of a balanced diet by providing healthy food education. ${ }^{68}$ Dieticians can aid patients in developing adoption of a balanced diet by providing healthy food education. Through a proper diet, greater weight loss can be achieved. ${ }^{69}$

To achieve a better quality of life, specific and concrete measures should be taken to address the underlying factors related to obesity. Surgical procedures are vital treatment options, which can give a better choice for overcoming obesity and its associated comorbidities. These bariatric surgeries are safe and effective. Guidance and awareness of the costs and side effects of these procedures can impact better public health by primary care physicians and healthcare workers. ${ }^{70}$

\section{Discussion}

The prevalence of OSA is increasing globally due to the growing occurrence of obesity in society. In obese people, the fat deposits in the upper respiratory tract make breathing difficulties during sleep thus causing OSA,,${ }^{71}$ OSA is strongly associated with obesity. ${ }^{72}$ Obese people must be screened for OSA and disorders that are associated with it. Both obesity and OSA patients have a greater risk of metabolic syndrome..$^{73}$ Diet control in obese people can improve sleep problems and associated depression, anxiety, and insomnia. In young adults, disturbed sleep management should be addressed along with stress and depression management. Keeping in mind that the attention should also be placed on emotional issues. Involving a person in 
healthy group discussions and therapies, encouraging them to actively participate in these groups, can strengthen psychological, mental and social health. Health care workers, especially primary care physicians, can play a vital role in solving this growing public health problem. ${ }^{74,75}$

OSA is a rising prevalent problem, associated mainly with obesity. The gold standard of treatment is CPAP therapy and ensuring that patients adhere to the therapy. If the condition does not improve, then surgical procedures are recommended to overcome this problem. ${ }^{76}$ Surgical weight loss procedures for obese people are highly recommended, even by non-surgical teams and societies. ${ }^{77}$ Bariatric surgical procedures are safe, even in the elderly population, so this should not be a deterrent to undergo the operations. ${ }^{78-80}$

\section{Conclusion}

This review highlights the impact of obesity on OSA is evident. Indeed, in several populations across different cultures, the positive relationship between obesity and OSA was pronounced. This represents an important public health crisis that demands multilayered interventions. To cope with this increasing and seriously preventable health issue, we emphasize the need to minimize the consumption of junk and fast food, increase the consumption of fresh fruits and vegetables. Other important habits are drinking water instead of juice, soda or alcohol; as well as smoking cessation. In addition to making dietary changes engaging in physical exercise is necessary. If medical and/or lifestyle medication therapies fail, then surgical interventions are another option to treat obesity and its associated comorbidities. Surgical procedures which can drastically reduce obesity and its related comorbidities ultimately improving mortality rates. To improve public health, obesity and its associated comorbidities should be seriously considered. Solving this issue is not only the responsibility of an individual and a healthcare worker, but it should be properly addressed by government officials to improve the health of individuals and make an overall healthier society.

\section{Acknowledgements and funding}

This work is supported by the following funding agencies: R25-HL105444 and R25-HL116378 (NHLBI); R01-MD007716 (NIMHD) to GJL. However, the funders had no role in study design, data collection or analysis.

\section{Conflicts of interest}

The authors declared that there are no conflicts of interest.

\section{References}

1. Watanabe M, Kikuchi H, Tanaka K, et al. Association of short sleep duration with weight gain and obesity at 1-year follow-up: a large-scale prospective study. Sleep. 2010;33(2):161-167.

2. Chen X, Pensuksan WC, Lohsoonthorn V, et al. Obstructive sleep apnea and multiple anthropometric indices of general obesity and abdominal obesity among young adults. Int J Soc Sci Stud. 2014;2(3):89-99.

3. Peppard PE, Young T, Palta M, et al. Longitudinal study of moderate weight change and sleep-disordered breathing. JAMA. 2000;284(23):3015-3021.

4. Senaratna CV, English DR, Currier D, et al. Sleep apnoea in Australian men: disease burden, co-morbidities, and correlates from the Australian longitudinal study on male health. BMC Public Health. 2016;16(Suppl 3):1029.
5. Sokwalla SM, Joshi MD, Amayo EO, et al. Quality of sleep and risk for obstructive sleep apnoea in ambulant individuals with type 2 diabetes mellitus at a tertiary referral hospital in Kenya: a cross-sectional, comparative study. BMC Endocr Disord. 2017;17(1):7.

6. Kuczmarski RJ, Flegal KM. Criteria for definition of overweight in transition: background and recommendations for the United States. Am J Clin Nutr. 2000;72(5):1074-1081.

7. Guilcher SJT, Kaufman-Shriqui V, Hwang J, et al. The association between social cohesion in the neighborhood and body mass index (BMI): An examination of gendered differences among urban-dwelling Canadians. Prev Med. 2017;99:293-298.

8. Vgontzas AN, Lin HM, Papaliaga M, et al. Short sleep duration and obesity: the role of emotional stress and sleep disturbances. Int $J$ Obes (Lond). 2008;32(5):801-809.

9. Vorona RD, Winn MP, Babineau TW, et al. Overweight and obese patients in a primary care population report less sleep than patients with a normal body mass index. Arch Intern Med. 2005;165(1):25-30.

10. Gangwisch JE, Malaspina D, Boden-Albala B, et al. Inadequate sleep as a risk factor for obesity: analyses of the NHANES I. Sleep. 2005;28(10):1289.

11. Kohatsu ND, Tsai R, Young T, et al. Sleep duration and body mass index in a rural population. Arch Intern Med. 2006;166(16):1701-1705.

12. Steinberg DM, Christy J, Batch BC, et al. Preventing weight gain improves sleep quality among black women: results from a RCT. Ann Behav Med. 2017;51(4):555-566.

13. Ko GT, Chan JC, Chan AW, et al. Association between sleeping hours, working hours and obesity in Hong Kong Chinese: the 'better health for better Hong Kong' health promotion campaign. Int $J$ Obes (Lond). 2007;31(2):254-260.

14. Baron KG, Reid KJ, Kim T, et al. Circadian timing and alignment in healthy adults: associations with BMI, body fat, caloric intake and physical activity. Int J Obes (Lond). 2016;41(2):203-209.

15. Chaput JP, Després JP, Bouchard C, et al. Short sleep duration is associated with reduced leptin levels and increased adiposity: results from the Quebec family study. Obesity (Silver Spring). 2007;15(1):253-261.

16. Cummings DE, Foster KE. Ghrelin-leptin tango in body-weight regulation. Gastroenterology. 2003;124(5):1532-1535.

17. Schwartz MW, Morton GJ. Obesity: keeping hunger at bay. Nature. 2002;418(6898):595-597.

18. Spiegel K, Leproult R, L'hermite-Balériaux M, et al. Leptin levels are dependent on sleep duration: relationships with sympathovagal balance, carbohydrate regulation, cortisol, and thyrotropin. J Clin Endocrinol Metab. 2004;89(11):5762-5771.

19. Taheri S, Lin L, Austin D, et al. Short sleep duration is associated with reduced leptin, elevated ghrelin, and increased body mass index. PLoS Med. 2004;1(3):e62.

20. Ayas NT, White DP, Al-Delaimy WK, et al. A prospective study of selfreported sleep duration and incident diabetes in women. Diabetes Care. 2003;26(2):380-384.

21. Horne J. Short sleep is a questionable risk factor for obesity and related disorders: statistical versus clinical significance. Biol Psychol. 2008;77(3):266-276.

22. Knutson KL, Spiegel K, Penev P, et al. The metabolic consequences of sleep deprivation. Sleep Med Rev. 2007;11(3):163-178.

23. Van Cauter E, Spiegel K, Tasali E, et al. Metabolic consequences of sleep 
and sleep loss. Sleep Med. 2008;9 (Suppl 1):S23-28.

24. Yaggi HK, Araujo AB, McKinlay JB. Sleep duration as a risk factor for the development of type 2 diabetes. Diabetes Care. 2006;29(3):657-661.

25. Harrison Y, Horne JA. Should we be taking more sleep? Sleep. 1995;18(10):901-907.

26. Destors M, Tamisier R, Galerneau LM, et al. Pathophysiology of obstructive sleep apnea syndrome and its cardiometabolic consequences. Presse Med. 2017;46(4):395-403.

27. Phillips BG, Kato M, Narkiewicz K, et al. Increases in leptin levels, sympathetic drive, and weight gain in obstructive sleep apnea. Am J Physiol Heart Circ Physiol. 2000;279(1):H234-237.

28. Jehan S, Auguste E, Zizi F, et al. Obstructive sleep apnea: women's perspective. J Sleep Med Disord. 2016;3(6).

29. Ulukavak Ciftci T, Kokturk O, Bukan N, et al. Leptin and ghrelin levels in patients with obstructive sleep apnea syndrome. Respiration. 2005;72(4):395-401.

30. Ozturk L, Unal M, Tamer L, et al. The association of the severity of obstructive sleep apnea with plasma leptin levels. Arch Otolaryngol Head Neck Surg. 2003;129(5):538-540.

31. Lurie A. Obstructive sleep apnea in adults: epidemiology, clinical presentation, and treatment options. Adv Cardiol. 2011;46:1-42.

32. Gami AS, Caples SM, Somers VK. Obesity and obstructive sleep apnea. Endocrinol Metab Clin North Am. 2003;32(4):869-894.

33. Sareli AE, Cantor CR, Williams NN, et al. Obstructive sleep apnea in patients undergoing bariatric surgery-a tertiary center experience. Obes Surg. 2011;21(3):316-327.

34. Bixler EO, Vgontzas AN, Lin HM, et al. Prevalence of sleep-disordered breathing in women: effects of gender. Am J Respir Crit Care Med. 2001;163(3 Pt 1):608-613.

35. Young T, Palta M, Dempsey J, et al. The occurrence of sleep-disordered breathing among middle-aged adults. $N$ Engl J Med. 1993;328(17):1230 1235 .

36. Basoglu OK, Tasbakan MS. Gender differences in clinical and polysomnographic features of obstructive sleep apnea: a clinical study of 2827 patients. Sleep Breath. 2017. p. 1-9.

37. Amin A, Ali A, Altaf QA, et al. Prevalence and associations of obstructive sleep apnea in south Asians and white Europeans with type 2 diabetes: a cross-sectional study. J Clin Sleep Med. 2017;13(4):583-589.

38. O'Connor GT1, Lind BK, Lee ET, et al. Variation in symptoms of sleepdisordered breathing with race and ethnicity: the Sleep heart health study. Sleep. 2003;26(1):74-79.

39. Redline S, Tishler PV, Hans MG, et al. Racial differences in sleepdisordered breathing in African-Americans and Caucasians. Am J Respir Crit Care Med. 1997;155(1):186-192.

40. Li KK, Kushida C, Powell NB, et al. Obstructive sleep apnea syndrome: a comparison between far $\square$ East Asian and White Men. Laryngoscope. 2000;110(10):1689-1693.

41. Vats MG, Mahboub BH, Al Hariri H, et al. Obesity and sleep-related breathing disorders in middle East and UAE. Canadian Respiratory Journal. 2016;2016:ID 9673054.

42. Kim NH, Lee SK, Eun CR, et al. Short sleep duration combined with obstructive sleep apnea is associated with visceral obesity in Korean adults. Sleep. 2013;36(5):723-729.

43. Le LK, Barendregt JJ, Hay P, et al. Prevention of eating disorders: A systematic review and meta-analysis. Clin Psychol Rev. 2017;53:46-58.
44. Kornet-van der Aa DA, Altenburg TM, van Randeraad-van der Zee CH, et al. The effectiveness and promising strategies of obesity prevention and treatment programmes among adolescents from disadvantaged backgrounds: a systematic review. Obes Rev. 2017;18(5):581-593.

45. Morgenthaler TI, Kapen S, Lee-Chiong T, et al. Practice parameters for the medical therapy of obstructive sleep apnea. Sleep. 2006;29(8):1031-1035.

46. Fitzpatrick SL, Stevens VJ. Adult obesity management in primary care, 2008-2013. Prev Med. 2017;99:128-133.

47. Verhoef SP, Camps SG, Gonnissen HK, et al. Concomitant changes in sleep duration and body weight and body composition during weight loss and 3-mo weight maintenance. Am J Clin Nutr. 2013;98(1):25-31.

48. Spaeth AM, Dinges DF, Goel N. Effects of experimental sleep restriction on weight gain, caloric intake, and meal timing in healthy adults. Sleep. 2013;36(7):981-990.

49. Fritscher LG, Canani S, Mottin CC, et al. Bariatric surgery in the treatment of obstructive sleep apnea in morbidly obese patients. Respiration. 2007;74(6):647-652.

50. Romero-Corral A, Caples SM, Lopez-Jimenez F, et al. Interactions between obesity and obstructive sleep apnea: implications for treatment. Chest. 2010;137(3):711-719.

51. Joosten SA, Hamilton GS, Naughton MT. Impact of weight loss management in OSA. Chest. 2017;152(1):194-203.

52. Axer S, Szabo E, Näslund I. Weight loss and alterations in co-morbidities after revisional gastric bypass: A case-matched study from the Scandinavian obesity surgery registry. Surg Obes Relat Dis. 2017;13(5):796-800.

53. Colquitt JL, Pickett K, Loveman E, et al. Surgery for weight loss in adults. Cochrane Database Syst Rev. 2014;8:CD003641.

54. Kothari SN, Borgert AJ, Kallies KJ, et al. Long-term (>10-year) outcomes after laparoscopic Roux-en-Y gastric bypass. Surg Obes Relat Dis. 2016;13(6):972-978.

55. Kienzl-Wagner K, Weissenbacher A, Gehwolf P, et al. Laparoscopic sleeve gastrectomy: gateway to kidney transplantation. Surg Obes Relat Dis. 2017;13(6):909-915.

56. Carlsson LMS, Sjöholm K, Karlsson C, et al. Long-term incidence of microvascular disease after bariatric surgery or usual care in patients with obesity, stratified by baseline glycaemic status: a post-hoc analysis of participants from the Swedish Obese Subjects study. Lancet Diabetes Endocrinol. 2017;5(4):271-279.

57. Tirado R, Masdeu MJ, Vigil L, et al. Impact of bariatric surgery on heme oxygenase-1, inflammation, and insulin resistance in morbid obesity with obstructive sleep apnea. Obes Surg. 2017;27(9):2338-2346.

58. Hudgel DW. Critical Review: CPAP and weight management of obstructive sleep apnea cardiovascular co-morbidities. Sleep Med Rev. 2016;37:14-23.

59. Baimas-George M, Hennings DL, Al-Qurayshi Z, et al. No more broken hearts: weight loss after bariatric surgery returns patients' postoperative risk to baseline following coronary surgery. Surg Obes Relat Dis. 2016;13(6):1010-1015.

60. Suriya Punchai, Zubaidah Nor Hanipah, Gautam Sharma, et al. Neurologic manifestations of vitamin B deficiency after bariatric surgery. Surgery for Obesity and Related Diseases. 2016;12(7):S107.

61. Valli PV, Gubler C. Review article including treatment algorithm: endoscopic treatment of luminal complications after bariatric surgery. Clin Obes. 2017;7(2):115-122.

62. Visscher TL, Lakerveld J, Olsen N, et al. Perceived health status: is obesity perceived as a risk factor and disease? Obes Facts. 2017;10(1):52-60. 
63. Brand-Miller JC, Barclay AW. Declining consumption of added sugars and sugar-sweetened beverages in Australia: a challenge for obesity prevention. Am J Clin Nutr. 2017;105(4):854-863.

64. Schwartz MB, Schneider GE, Choi YY, et al. Association of a community campaign for better beverage choices with beverage purchases from supermarkets. JAMA Intern Med. 2017;177(5):666-674.

65. Lora KR, Cheney M, Branscum P. Hispanic mothers' views of the fathers' role in promoting healthy behaviors at home: Focus group findings. $J$ Acad Nutr Diet. 2017;117(6):914-922.

66. Horne J. Obesity and short sleep: unlikely bedfellows? Obes Rev. 2011;12(5):84-94.

67. Zhang Q, Chen X, Liu Z, et al. Diet diversity and nutritional status among adults in southwest China. PLoS One. 2017;12(2):e0172406.

68. Bąk-Sosnowska M, Skrzypulec-Plinta V. Health behaviors, health definitions, sense of coherence, and general practitioners' attitudes towards obesity and diagnosing obesity in patients. Arch Med Sci. 2017;13(2):433440.

69. Sun Y, You W, Almeida F, et al. The effectiveness and cost of lifestyle interventions including nutrition education for diabetes prevention: a systematic review and meta-analysis. J Acad Nutr Diet. 2017;117(3):404 421.

70. Brousseau H, Pohl D. Quality improvement processes in obesity surgery lead to higher quality and value, lower costs. R I Med J. 2017;100(2):2830 .

71. Lim DC, Pack AI. Obstructive sleep apnea: update and future. Annu Rev Med. 2016;68:99-112.
72. Glicksman A, Hadjiyannakis S, Barrowman N, et al. Body fat distribution ratios and obstructive sleep apnea severity in youth with obesity. $J$ Clin Sleep Med. 2017;13(4):545-550.

73. Patinkin ZW, Feinn R, Santos M. Metabolic consequences of obstructive sleep apnea in adolescents with obesity: a systematic literature review and meta-analysis. Child Obes. 2017;13(2):102-110.

74. Tan X, Alén M, Wang K, et al. Effect of six-month diet intervention on sleep among overweight and obese men with chronic insomnia symptoms: a randomized controlled trial. Nutrients. 2016;8(11).

75. Wallace DD, Boynton MH, Lytle LA. Multilevel analysis exploring the links between stress, depression, and sleep problems among two-year college students. J Am Coll Health. 2017;65(3):187-196.

76. Cao MT, Sternbach JM, Guilleminault C. Continuous positive airway pressure therapy in obstuctive sleep apnea: benefits and alternatives. Expert Rev Respir Med. 2017;11(4):259-272.

77. Pohl D, Bloomenthal A. Diabetes, obesity, and other medical diseases-is surgery the answer. $R$ I Med J. 2017;100(2):15-17.

78. Quirante FP, Montorfano L, Rammohan R, et al. Is bariatric surgery safe in the elderly population? Surg Endosc. 2016;31(4):1538-1543.

79. Raveendran R, Wong J, Singh M, et al. Obesity hypoventilation syndrome, sleep apnea, overlap syndrome: perioperative management to prevent complications. Curr Opin Anaesthesiol. 2017;30(1):146-155.

80. Hou C, Zheng B, Yang Y, et al. Weight reduction via life-style modifications results in reverse remodelling and cardiac functional improvement in a patient with obesity. Obes Res Clin Pract. 2017;11(3):364-369. 